\title{
Variação na estrutura foliar de guabiroba (Campomanesia xanthocarpa Berg.) sob diferentes condições de luminosidade em um remanescente de Floresta Ombrófila Mista
}

\author{
Variation in leaf structure of guabiroba (Campomanesia xanthocarpa Berg.) \\ under different lighting conditions in a remnant of Araucaria Forest
}

\author{
Rogério Antonio Krupek ${ }^{1 *}$ \\ Adriane Grade de Lima²
}

Resumo

O presente estudo, desenvolvido em uma área de Floresta Ombrófila Mista pertencente ao Parque Municipal das Araucárias, situado em Guarapuava (PR), teve como finalidade avaliar algumas características morfológicas e anatômicas da folha da guabiroba (Campomanesia xanthocarpa Berg.) expostas, em ambiente natural, a diferentes condições de luminosidade. Neste sentido, foram realizadas coletas em três ambientes distintos: aberto (pleno sol), meia sombra (áreas de trilhas do parque) e sombreado (mata fechada). As amostragens foram realizadas em maio de 2009 , sendo que para cada um dos ambientes foram selecionados cinco indivíduos e retirados de cada um deles um total de vinte folhas. As variáveis morfológicas avaliadas foram comprimento e largura foliar, massa fresca, massa seca, conteúdo de água, área foliar, área específica foliar, conteúdo de água/área foliar e densidade estomática. As variáveis anatômicas mensuradas foram epiderme adaxial e abaxial, espessura foliar e do mesófilo, espessura do parênquima paliçádico e lacunoso e relação paliçádico/lacunoso. Os maiores valores médios de área foliar e menores de massa seca e densidade estomática foram obtidos para plantas ocorrentes em ambiente sombreado, as quais são características comuns de plantas adaptadas a este tipo de ambiente. A Análise dos Componentes Principais apresentou um grupo bem definido, com base nas características anatômicas, para as plantas ocorrentes em local sombreado. Os ambientes meia-sombra e aberto apresentaram similaridade, demonstrando a influência da presença de energia luminosa, mesmo em pequena quantidade, na organização estrutural da folha de C. xanthocarpa.

Palavras-chave: guabirobeira; luz; estrutura foliar.

I Dr.; Biólogo; Professor da Faculdade Estadual de Filosofia, Ciências e Letras de União da Vitória, FAFIUV; Endereço: Praça Coronel Amazonas s.n., CEP: 84600-000, União da Vitória, Paraná, Brasil; E-mail: rogeriokrupek@yahoo.com.br $(*)$ Autor para correspondência.

2 Graduanda em Biologia na Faculdade Guairacá, Endereço: Rua XV de Novembro, 7050, Centro, CEP: 85010 000, Guarapuava, Paraná, Brasil; E-mail: adrigradelima@yahoo.com.br 


\section{Abstract}

The present study was developed in a reminiscent of Mixed Ombrophylous Forest that compose the Araucaria Municipal Park, located in Guarapuava (PR). The aim of this study was to evaluate some morphological and anatomy leaves characteristics of guabiroba (Campomanesia xanthocarpa Berg.) exposed in the natural environment, the different lighting conditions. In this sense, collections were made in three distinct environments: open (full sun), half shade (areas of the park's trails) and shaded (closed forest). The samples were collected in May 2009, and for each of the environments were selected five individuals and removed from each of them a total of 20 leaves. The morphological variables evaluated were leaf length and width, fresh weight, dry weight, water content, leaf area, specific leaf area, water content, leaf area and stomatal density. The anatomical variables measured were adaxial and abaxial epidermis, leaf thickness and mesophyll thickness, palisade and spongy parenchyma palisade/spongy ratio. The higher mean values of leaf area and lower dry matter and stomatal density were obtained for plants occurring in the shaded, which are common characteristics of plants adapted to this type of environment. The Principal Component Analysis showed a well-defined group, based on anatomical characteristics to the plants occurring in shady places. The half-shadow and open environments had similar, showing the influence of the presence of light energy, even in small quantities in the structural organization of the leaf of C. xanthocarpa.

Key words: guabirobeira; light; leaf structure.

\section{Introdução}

A Floresta Ombrófila Mista, também conhecida como Floresta de Pinheiros ou de Araucárias (KLEIN, 1984), é caracterizada pela presença dominante de Araucaria angustifolia (Bert.) O. Kuntze, além de vários representantes de algumas famílias típicas, como por exemplo, a guabirobeira (Campomanesia xanthocarpa Berg., Myrtaceae). Esta formação é parte do bioma Mata Atlântica possuindo altos níveis de diversidade, atualmente intensamente explorado (LIMA; CAPOBIANCO, 1997).

A maioria das formações vegetacionais brasileiras apresentam as Myrtaceae como uma das famílias mais comuns da sua flora (SOUZA; LORENZI, 2005). Na Floresta de Araucária, C. Xanthocarpa Berg., entre outras espécies desta família, são facilmente encontradas em grande abundância. Trabalhos florísticos e fitossociológicos realizados em diferentes regiões do país citam a presença da guabiroba como espécie comumente ocorrente em diferentes formações vegetacionais (BARDDAL et al., 2003; FARIAS et al., 1994; IVANAUSKAS et al., 1999; CARDOSO-LEITE et al., 2004; SILVA; MARCONI, 1990). Cordeiro e Rodrigues (2007) realizaram um estudo fitossociológico na mesma área de estudos do presente trabalho e encontraram $C$. xanthocarpa como a espécie mais abundante na região. Tal constatação demonstra a importância desta espécie na flora local.

Campomanesia xanthocarpa Berg. é uma espécie frutífera de hábito arbóreo, ocorrendo desde o estado de Minas Gerais 
até o Rio Grande do Sul. É uma espécie heliófita, seletiva higrófita, até mesófita, sendo bastante frequente na Floresta Ombrófila Mista, especialmente nos solos úmidos da floresta fluvial, nos capões, e em áreas mais abertas da floresta secundária (REITZ,1977). É conhecida popularmente como guabirobeira, guavirova ou guabiroba do mato e apresenta-se como arbusto, arvoreta ou árvore de 10 a $20 \mathrm{~m}$ de altura e até $60 \mathrm{~cm}$ de diâmetro. As folhas são verdes e opostas, simples, membranáceas, ovalado-oblongas, medindo de $4-10 \mathrm{~cm}$ de comprimento por 3-4,5 cm de largura (CORREA, 1974; MATTOS, 1984). As flores são melíferas, de cor branca e os frutos são do tipo baga, globoso, de coloração amarelada. Os frutos são de formato redondo e de cor verde quando jovens e amarelos e adocicados quando maduros. O tipo de dispersão é zoocórica atraindo, principalmente, as aves, dentre as quais: os sabiás, saíras e sanhaços (FRISCH; FRISCH, 2005). C. xanthocarpa pode ser utilizada como espécie ornamental e é indicada para plantio em áreas degradadas.

Os fatores ambientais onde as plantas encontram-se interferem diretamente no desenvolvimento delas, apresentando inclusive, relações com a sua morfologia e anatomia. Entre estes fatores, a luz é um agente de extrema importância interferindo no crescimento e desenvolvimento das plantas, via fotossíntese e morfogênese (CASTRO et al., 2003). Estudos que relacionam características morfológicas e anatômicas foliares com variações na intensidade lumiosa tem sido recentemente realizados, principalmente para plantas de interesse comercial (CAMPOS; UCHIDA, 2002; MILANEZE-GUTIERRE et al., 2003; MORAIS et al.,2004; MONTANARI et al., 2004). Tais estudos forneceram informações importantes sobre a ação da variação na energia luminosa e podem ser importantes em futuros estudos de manejo de ambientes degradados ou ainda na produção em cultivo de espécies frutíferas, como é o caso da guabirobeira.

Considerando a importância desta espécie na flora local da região em estudo, o presente trabalho tem por objetivo avaliar algumas características morfológicas e anatômicas da folha de C. Xanthocarpa em diferentes condições de luminosidade em que se desenvolvem em estado natural.

\section{Materiais e Métodos}

A área de estudos é um remanescente de Floresta Ombrófila Mista (FOM) em boas condições de preservação, o qual se constitui do Parque Municipal das Araucárias (25 21' $06^{\prime \prime}$ S e $51^{\circ} 28^{\prime} 08^{\prime \prime} \mathrm{W}$ ), localizado no município de Guarapuava, região centro sul do estado do Paraná (Figura 1).

A área total do parque é de aproximadamente 104 ha, com 41 ha ocupados pela FOM. O clima da região, segundo a classificação de Köeppen, é do tipo Cfb, sem estação seca (MAACK, 1981). Segundo os dados fornecidos pela Secretaria de Agricultura e Abastecimento do município de Guarapuava, para o ano de 2009, a temperatura média anual do município foi de $23,3^{\circ} \mathrm{C}$, sendo a maior temperatura média durante o mês de novembro $\left(18,3^{\circ} \mathrm{C}\right)$ e a menor durante o mês de junho $\left(12,4^{\circ} \mathrm{C}\right)$. A média anual de umidade relativa do ar foi de $79 \%$ e a precipitação anual total foi de $2.188,8 \mathrm{~mm}$, sendo setembro o mês de maior precipitação média, com $329,0 \mathrm{~mm}$ e abril o de menor, com $67,8 \mathrm{~mm}$, sem ocorrência de deficiência hídrica. $\mathrm{Na}$ área, predominam os solos do tipo Latossolo Bruno Álico. O relevo varia de plano a médio ondulado e a altitude fica em torno de 1.070 metros (GUARAPUAVA, 2010). 


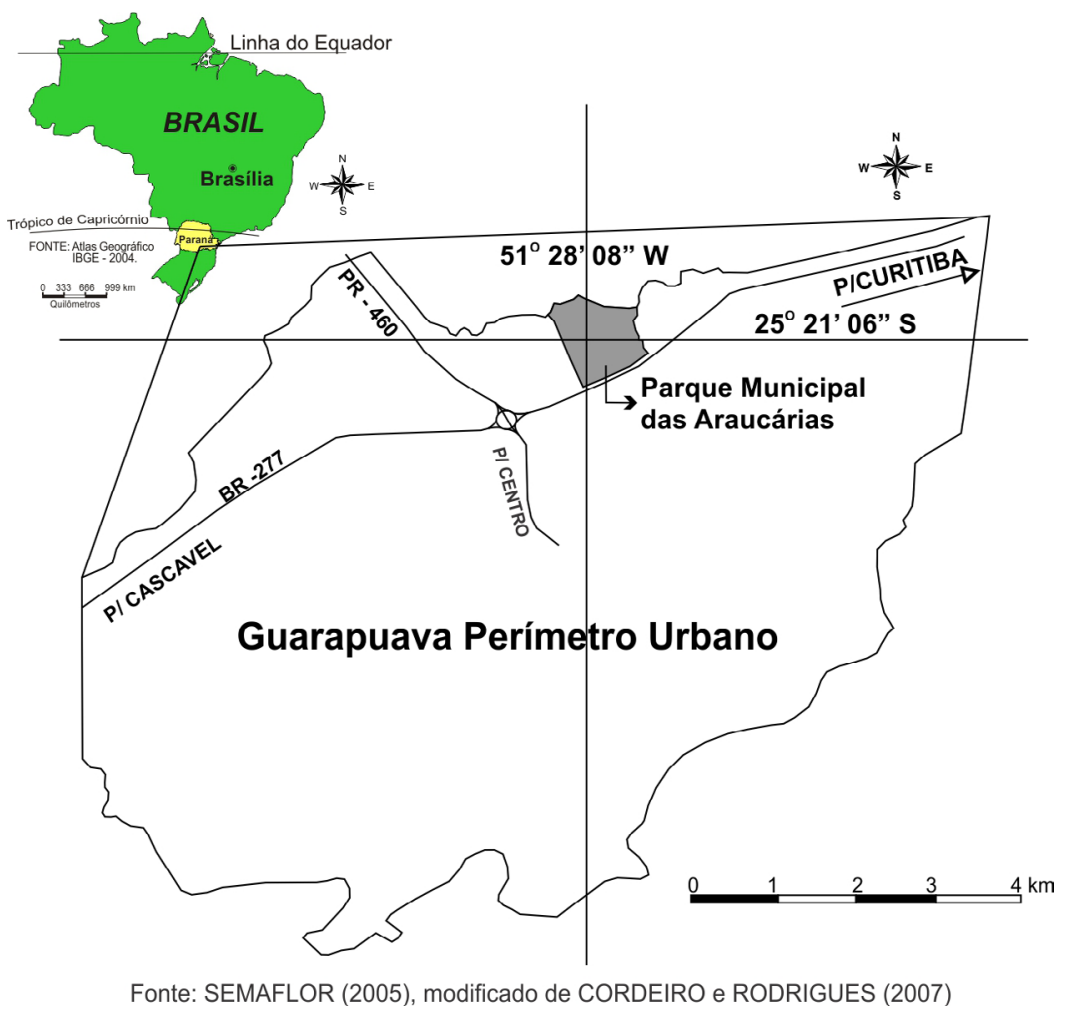

Figura I. Localização do Parque das Araucárias, dentro do perímetro urbano do município de Guarapuava, Paraná, Brasil

Dentro da área de estudos, foram selecionadas visualmente três áreas com diferentes condições de luminosidade e que apresentavam representantes de C.xanthocarpa: I) aberto (sol pleno), com a incidência direta de energia luminosa (100\% de incidência); II) meia-sombra, representado pelas áreas de trilhas, com a incidência de luz menos conspícua (62\% de incidência); III) sombra, representado pela área de mata fechada, com forte restrição na incidência de luz (33\% de incidência). As medições de irradiância foram tomadas com um luxímetro (Licor LI 250A) em alguns pontos de cada um dos ambientes, sendo posteriormente feita a média e transformada em porcentagem de incidência, com o ambiente aberto representando 100\%. Em cada um dos ambientes foram amostrados aleatoriamente cinco indivíduos de C. xanthocarpa com altura entre três a sete metros.
Todas as coletas foram realizadas no dia 28 de maio de 2009. Foram coletadas oito folhas totalmente expandidas de cada indivíduo, totalizando quarenta folhas em cada um dos ambientes avaliados. Estas foram retiradas do terceiro ao sexto nós no sentido ápice-base.

Em campo, vinte folhas de $C$. xanthocarpa por ambiente foram umedecidas e acondicionadas em sacos plásticos para mensuração de suas massas frescas em balança analítica. Posteriormente, estas folhas foram prensadas em papel jornal e desidratadas em estufa a $50^{\circ} \mathrm{C}$, até atingirem massa constante para a mensuração de suas respectivas massas secas. O conteúdo de água da folha foi calculado pela diferença entre massa fresca e seca foliar. Das folhas secas, a área foliar foi estimada utilizando-se a imagem digitalizada em scanner de mesa acoplado a computador, 
com auxilio do programa Autocad Map - Autodesk Map 5 (Copyright@ 2000 Earth Resource Mapping, Inc). A partir dos dados de área e massa seca foliar foi estimada a área específica foliar $\mathrm{AEF}=$ área foliar $\left(\mathrm{cm}^{2}\right) /$ massa seca $(\mathrm{g})$. Foram tomadas ainda medidas de comprimento e largura de cada folha. A densidade estomática foi calculada utilizando-se a modelagem com esmalte incolor no terço médio foliar. Moldes epidérmicos foram montados em lâmina e lamínula e as densidades foram determinadas através da contagem de estômatos situados em vinte campos de uma área de $1 \mathrm{~mm}^{2}$.

Vinte amostras do terço médio foliar por ambiente foram coletadas para mensuração da espessura dos tecidos, descrição e análise anatômica, sendo estas fixadas em FAA 70 (etanol 70\%, formaldeído e ácido acético 18:1:1 v/v) (JOHANSEN, 1940) e posteriormente conservadas em álcool 70\%. As mensurações da espessura do limbo e dos tecidos foram realizadas em microscópio óptico provido de escala micrometrada. Para descrição anatômica, secções paradérmicas e transversais do terço médio foram obtidas à mão livre, coradas com azul de toluidina $0,5 \%$ e montadas entre lâmina e lamínula. Posteriormente lâminas semipermanentes foram confeccionadas, coradas com azul de toluidina (ALVES de BRITO; ALQUINI, 1996) e vedadas em meio de montagem.

Para todas as variáveis das características morfológicas e anatômicas, foram calculadas as médias e os respectivos desvios padrão. Para avaliar as possíveis diferenças entre os ambientes foi realizada a análise de variância e as médias foram comparadas pelo teste de Tukey a $5 \%$ de probabilidade. Todas as características anatômicas foram relacionadas através do coeficiente de correlação $r$ de Pearson. A análise dos componentes principais
(PCA) foi utilizada, com base em todas as características anatômicas analisadas, buscando no conjunto de dados possíveis associações entre os ambientes estudados.

\section{Resultados e Discussão}

Dentre as características morfológicas avaliadas, a maioria delas apresentou uma alta variação nos seus valores quantitativos (Tabela 1), indicando certa variabilidade dentro da espécie ocorrente nos diferentes ambientes.

Boeger et al. (2006) afirmam que algumas características morfológicas, assim como maior área foliar e menor massa seca e densidade estomática são características comuns de plantas adaptadas a regiões com menor disponibilidade de energia luminosa. Tais características estão de acordo com os valores obtidos para as folhas de C. xanthocarpa, entretanto, estas não apresentaram diferenças significativas entre os ambientes, com exceção à densidade estomática. Dessa forma, é provável que outros fatores ambientais (p.ex. altitude, disponibilidade hídrica do solo ou nutrientes) também exerçam alguma influência sobre as características foliares (BOEGER et al., 2005; RÔÇAS et al., 1997). Segundo Castro Diez et al. (2000), é comum a ocorrência de valores elevados de massa seca foliar em plantas que se desenvolvem em ambientes a pleno sol, entretanto, a ausência de diferença significativa pode ser provavelmente devido a maior área foliar média obtida para as folhas no tratamento sombreado e meia-sombra (ESPÍNDOLA JUNIOR et al., 2009). Os maiores valores de AEF nestes tratamentos reafirmam tal constatação. A maior densidade estomática por sua vez, obtida para as folhas de ambiente aberto, estão obviamente relacionadas à maior disponibilidade de energia luminosa. 
Tabela I. Valores médios e respectivos desvios padrão das características morfológicas $(n=20)$ das folhas de Campomanesia xanthocarpa nos diferentes ambientes

\begin{tabular}{lccc}
\hline & $\begin{array}{c}\text { Ambiente } \\
\text { aberto }\end{array}$ & $\begin{array}{c}\text { Ambiente } \\
\text { sombreado }\end{array}$ & $\begin{array}{c}\text { Ambiente } \\
\text { meia-sombra }\end{array}$ \\
\hline Comprimento foliar $(\mathrm{cm})$ & $8,60 \pm 0,96 \mathrm{a}$ & $8,66 \pm 1,02 \mathrm{a}$ & $8,72 \pm 1,37 \mathrm{a}$ \\
Largura foliar $(\mathrm{cm})$ & $4,34 \pm 0,39 \mathrm{a}$ & $4,82 \pm 0,6 \mathrm{~b}$ & $4,71 \pm 0,63 \mathrm{ab}$ \\
Massa fresca $(\mathrm{g})$ & $0,41 \pm 0,11 \mathrm{a}$ & $0,48 \pm 0,1 \mathrm{ab}$ & $0,54 \pm 0,11 \mathrm{~b}$ \\
Massa seca $(\mathrm{g})$ & $0,19 \pm 0,05 \mathrm{a}$ & $0,18 \pm 0,04 \mathrm{a}$ & $0,18 \pm 0,06 \mathrm{a}$ \\
Conteúdo de água $(\mathrm{g})$ & $0,22 \pm 0,07 \mathrm{a}$ & $0,30 \pm 0,06 \mathrm{~b}$ & $0,36 \pm 0,06 \mathrm{c}$ \\
Área foliar $\left(\mathrm{cm}^{2}\right)$ & $17,11 \pm 3,35 \mathrm{a}$ & $18,34 \pm 4,17 \mathrm{a}$ & $18,92 \pm 4,73 \mathrm{a}$ \\
Conteúdo de água/Área foliar $\left(\mathrm{mg} \cdot \mathrm{cm}^{-2}\right)$ & $12,80 \pm 2,96 \mathrm{a}$ & $16,57 \pm 2,19 \mathrm{~b}$ & $19,48 \pm 2,17 \mathrm{c}$ \\
Área específica foliar $\left(\mathrm{cm}^{2} \cdot \mathrm{g}^{-1}\right)$ & $96,39 \pm 20,8 \mathrm{a}$ & $100,27 \pm 10,97 \mathrm{~b}$ & $108,21 \pm 16,54 \mathrm{c}$ \\
Densidade estomática abaxial $\left(\right.$ no.mm $\left.\mathrm{mm}^{-2}\right)$ & $197,5 \pm 28,06 \mathrm{a}$ & $145,65 \pm 17,19 \mathrm{~b}$ & $136,45 \pm 21,69 \mathrm{bc}$ \\
\hline Noc:Mas
\end{tabular}

Nota: Médias seguidas da mesma letra nas linhas não diferem entre si pelo teste de Tukey a $5 \%$ de probabilidade.

Os valores médios de largura foliar apresentaram diferenças significativas entre os ambientes aberto e sombreado $(F=4,14 ; p<0,05)$, enquanto que massa fresca foliar diferiu entre os ambientes aberto e meia sombra $(F=8,51 ; p<0,001)$. Os valores quantitativos de conteúdo de água e conteúdo de água por área foliar foram significativamente diferentes $(F=36,96$; $p<0,001)$ entre todos os ambientes avaliados. Densidade estomática, por sua vez, mostrou diferença significativa $(F=41,85 ; p<0,05)$ entre os ambientes aberto e sombreado e aberto e meia-sombra (Tabela 1). Segundo Boeger et al. (2008), plantas ocorrentes nas áreas de sub-bosque na Floresta Ombrófila Mista apresentam maior tamanho foliar, devido à maior dificuldade na captação de energia luminosa, menos intensa nestes ambientes. Neste sentido, os valores mais elevados da largura foliar principalmente nos ambientes sombreados parecerem responder exatamente a esta limitação, uma vez que, quanto maior a área foliar expandida maior a quantidade de luz em contato com a mesma. Embora não tenham sido observadas diferenças significativas, os valores de área foliar também foram maiores nestes ambientes. A maior quantidade de água presente nas folhas das plantas de ambiente sombreado e meiasombra ocorrem, provavelmente, em função do maior tamanho das mesmas. As plantas de sol, de modo contrário, tendem a perder maior quantidade de água via transpiração, fato este que faz com que invistam menos na formação de uma maior superfície foliar, uma vez que a energia luminosa presente nestes ambientes é abundante e não compromete o processo fotossintético (ESPÍNDOLA JÚNIOR et al., 2009). Tal predição explicaria os menores valores de área foliar e conteúdo de água obtido para as folhas de ambiente aberto. Segundo Wilson et al. (1999), as plantas que apresentam características como as descritas acima para as folhas de ambiente aberto, em especial menor área foliar e maior massa seca, indicam uma maior quantidade de tecidos mecânicos nestas folhas. De modo contrário, as folhas com maiores áreas e menores massas secas, assim como obtido para as folhas de ambiente sombreado, tendem a produzir uma maior quantidade 
de tecidos fotossintetizantes (BOEGER et al., 2006). Tal fato se confirma pelas maiores espessuras obtidas dos parênquimas paliçádico e lacunoso nas folhas de ambiente sombreado (Tabela 2). ambiente exposto ao sol pleno. Outro fator também relevante neste caso foi a disponibilidade hídrica local, a qual entretanto, na região de estudos do presente trabalho não apresenta-se como fator limitante e talvez

Tabela 2. Valores médios e respectivos desvios padrão das características anatômicas $(n=20)$ das folhas de Campomanesia xanthocarpa nos diferentes tratamentos

\begin{tabular}{lccc}
\hline \multicolumn{1}{c}{ Espessuras do limbo } & $\begin{array}{c}\text { Ambiente } \\
\text { aberto }\end{array}$ & $\begin{array}{c}\text { Ambiente } \\
\text { sombreado }\end{array}$ & $\begin{array}{c}\text { Ambiente } \\
\text { meia-sombra }\end{array}$ \\
\hline Total do limbo $(\mu \mathrm{m})$ & $146,25 \pm 14,22 \mathrm{a}$ & $159,0 \pm 25,83 \mathrm{ab}$ & $135,75 \pm 10,79 \mathrm{ac}$ \\
Mesofilo $(\mu \mathrm{m})$ & $118,0 \pm 13,61 \mathrm{a}$ & $131,0 \pm 24,26 \mathrm{ab}$ & $109, \pm 10,71 \mathrm{ac}$ \\
Parênquima paliçádico $(\mu \mathrm{m})$ & $47,0 \pm 5,71 \mathrm{a}$ & $56,50 \pm 11,37 \mathrm{~b}$ & $45,0 \pm 6,07 \mathrm{ac}$ \\
Parênquima lacunoso $(\mu \mathrm{m})$ & $71,0 \pm 11,65 \mathrm{a}$ & $73,50 \pm 14,96 \mathrm{ab}$ & $64,0 \pm 8,83 \mathrm{ac}$ \\
Epiderme: face abaxial $(\mu \mathrm{m})$ & $11,75 \pm 2,45^{\mathrm{a}}$ & $11,0 \pm 2,05 \mathrm{a}$ & $11,0 \pm 2,05^{\mathrm{a}}$ \\
Epiderme: face adaxial $(\mu \mathrm{m})$ & $16,50 \pm 3,28^{\mathrm{a}}$ & $16,50 \pm 4,32^{\mathrm{a}}$ & $13,75 \pm 3,35^{\mathrm{a}}$ \\
Razão paliçádico - lacunoso & $0,68 \pm 0,13 \mathrm{a}$ & $0,78 \pm 0,16 \mathrm{a}$ & $0,71 \pm 0,13 \mathrm{a}$ \\
\hline
\end{tabular}

Nota: Médias seguidas da mesma letra nas linhas não diferem entre si pelo teste de Tukey a $5 \%$ de probabilidade.

Dentro dos ambientes, todas as características morfológicas da folha de $C$. xanthoarpa, exceção feita às variáveis largura e conteúdo de água em ambiente aberto, apresentaram correlações positivas e significativas entre si. Tal constatação demonstra um padrão de crescimento foliar homogêneo.

Para todas as características anatômicas mensuradas (Figura 2), os valores nominais obtidos apresentaram-se relativamente distintos considerando os diferentes ambientes avaliados (Tabela 2). Apenas os valores de espessura da epiderme (tanto abaxial quanto adaxial) e a relação parênquima paliçádico/ lacunoso não apresentaram diferenças significativas entre os tratamentos avaliados. Segundo Mantuano et al. (2006) as diferenças anatômicas obtidas dentro de uma mesma população de Erythroxylum ovalifolium (Erythroxylaceae) podem ser respostas a mudanças no regime de luz disponível. Neste caso, em particular, foram obtidos valores maiores de espessura da epiderme adaxial em tenha sido responsável pela aproximação nos valores da espessura da epiderme. A razão parênquima paliçádico/lacunoso se manteve abaixo de 1 para todos os tratamentos (Tabela 2 ), característica que se apresenta vantajosa em ambientes com menor disponibilidade de luz,já que o parênquima lacunoso absorve com maior eficiência a luz difusa, presente em maior quantidade nos ambientes bosque e sub-bosque, devido a trajetória aleatória da luz dentro deste tipo de tecido (ESPÍNDOLA JÚNIOR et al., 2009; BOEGER et al., 2008). Característica inversa se esperaria no ambiente aberto, com maior disponibilidade de luz, entretanto, tal fato não foi observado, assim como nos trabalhos acima citados.

Os demais parâmetros mensurados mostraram diferenças significativas entre os ambientes. Neste sentido, a espessura total do limbo diferiu entre sombreado e meia sombra $(F=8,24 ; p<0,001)$. A espessura do mesófilo também apresentou diferença entre os ambientes sombreado 


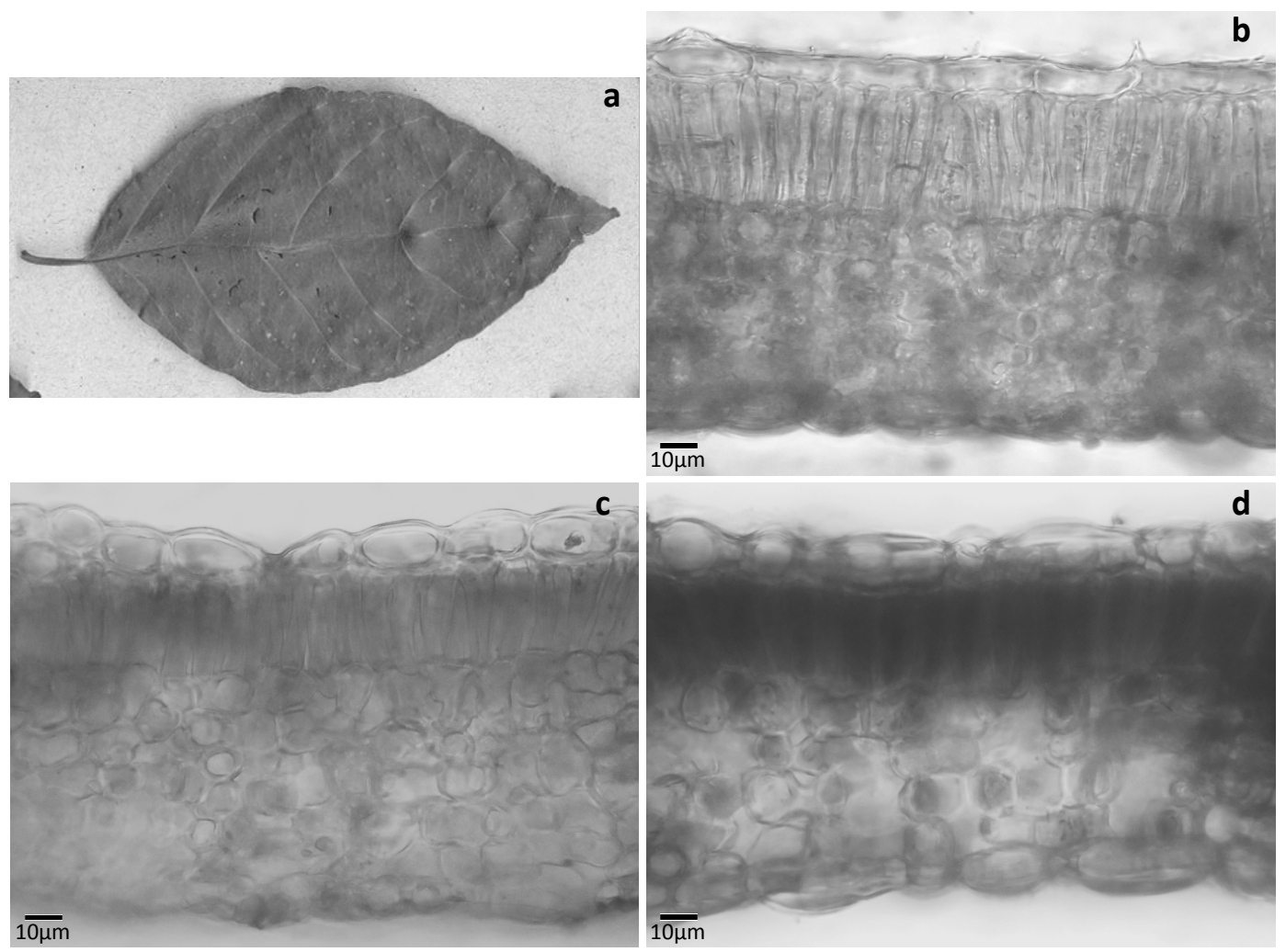

Figura 2. Detalhe da folha de Campomanesia xanthocarpa (a) e seções transversais da lâmina foliar obtida nos diferentes ambientes: (b) aberto; (c) meia sombra; (c) sombreado

e meia sombra $(F=8,26 ; p<0,001)$. Para os valores de parênquima paliçádico foram obtidas diferenças significativas entre os ambientes aberto e sombreado e meia sombra e sombreado $(F=11,4 ; p<0,001)$. Parênquima lacunoso por sua vez diferiu entre os ambientes meia-sombra e sombreado $(F=3,32 ; p<0,05)$ (Tabela 2). Para todas estas variáveis, os valores mais elevados foram obtidos para o tratamento sombreado, o qual se apresenta contrário ao obtido em outros estudos semelhantes (ESPÍNDOLA JÚNIOR et al., 2009; BOEGER et al., 2008; MANTUANO et al., 2006). De um modo geral, o aumento na dimensão da lâmina foliar, principalmente representado pelos tecidos fotossintetizantes é resultado da ação de uma intensidade luminosa elevada, favorecendo um consequente aumento na atividade fotossintética. Além do maior desenvolvimento do parênquima lacunoso nas folhas desenvolvidas no ambiente sombreado, já esperado como discutido acima, o parênquima paliçádico também se apresentou mais espesso que nos demais tratamentos. Tal característica facilita a passagem da energia luminosa no interior da folha garantindo maiores taxas fotossintéticas (VOGELMANN et al.,1996) e a associação entre estas propriedades das folhas de C. xanthocarpa em ambiente sombreado, levando a formação de uma lâmina foliar espessa, pode garantir maior aproveitamento da radiação luminosa que chega normalmente em menor quantidade em regiões de bosque e sub-bosque. 
Da mesma forma como obtido para as caraterísticas morfológicas, as medidas anatômicas tomadas da folha de C.xanthoarpa apresentaram várias correlações significativas entre si, dentro de todos os tratamentos avaliados, o que demonstra mais uma vez a interrelação das diferentes características avaliadas.

A Análise de Componentes Principais (PCA) mostrou que os dois primeiros eixos explicaram $71 \%$ da variância total (Figura 3 e Tabela 3). Espessura total do limbo e espessura do mesófilo foram as variáveis mais relacionadas com o eixo 1 , explicando $48 \%$ da variância. O eixo 2 explicou $23 \%$ da variância, sendo que a variável mais relacionada foi relação parênquima paliçádico/lacunoso (Tabela 3). Para o eixo 1, as medidas foliares do tratamento sombreado apresentaram um agrupamento relativamente homogêneo, com valores mais elevados de espessura total do limbo e do mesófilo, enquanto que os tratamentos meia sombra e aberto mostraram uma ordenação similar com

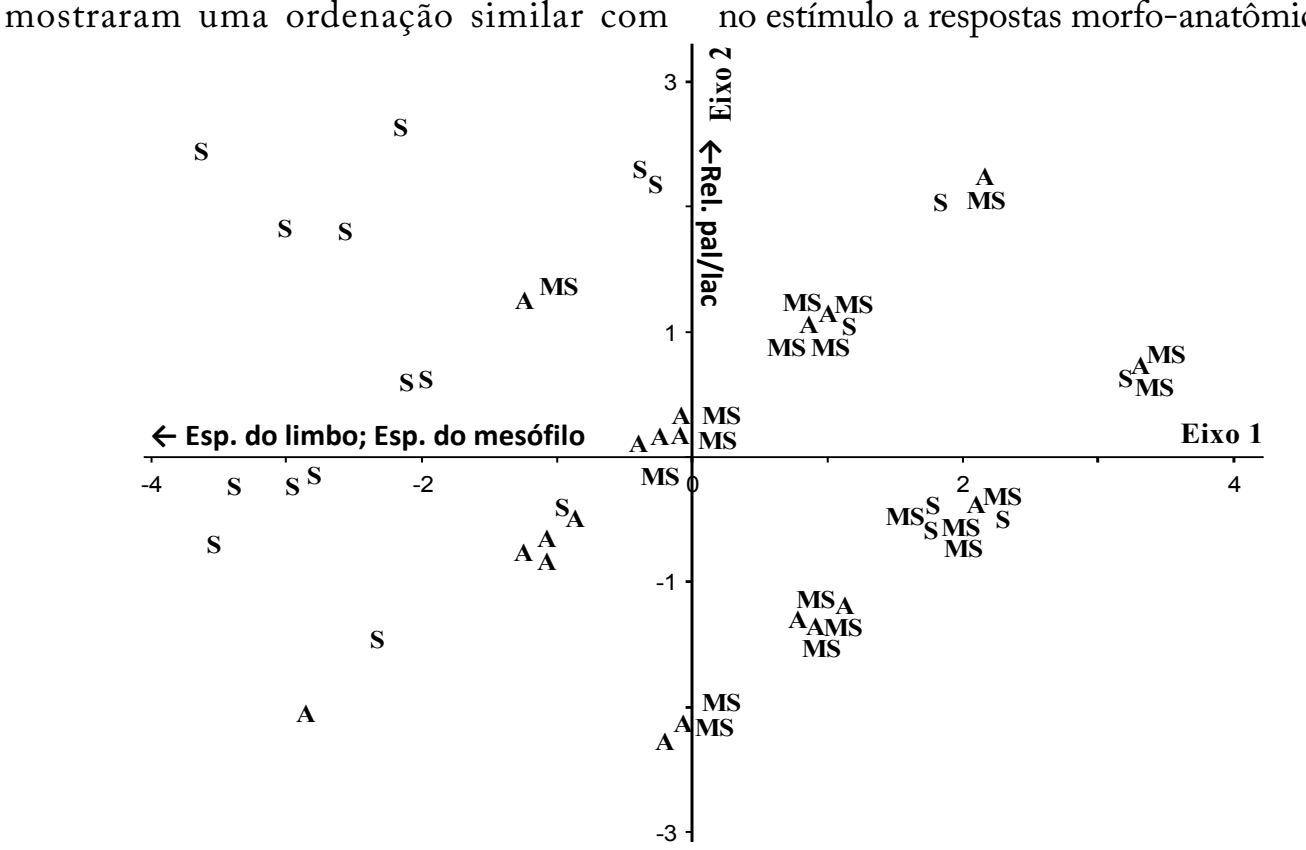

Figura 3. Ordenação da Análise de Componentes Principais (PCA) para as características anatômicas características contrárias. Para o eixo 2, não se verificaram distinções nítidas entre os diferentes tratamentos, estando os pontos ordenados de modo similar (Figura 3).

A ordenação obtida reforça as diferenças já enfatizadas pela análise de variância, mostrando que as plantas que se desenvolvem em ambiente sombreado apresentaram as características anatômicas mais distintas, basicamente relacionadas com a espessura da lâmina foliar e consequentemente dos tecidos parenquimáticos constituintes do mesófilo. Neste sentido, a disponibilidade de energia luminosa, basicamente representada pelas suas baixas taxas parece ser um fator de modelação da estrutura foliar. A ausência de diferença entre os ambientes aberto e meia sombra pode ser devido relativamente boa quantidade de radiação luminosa que chega até o interior da mata promovido pelas áreas de trilhas criadas dentro do parque. Tal resultado mostra ainda que relativamente baixas taxas de energia luminosa disponível são suficientes no estímulo a respostas morfo-anatômicas.

\footnotetext{
de C.xanthoarpa nos tratamentos aberto (A), meia sombra (MS) e sombreado (S)
} 
Tabela 3. Resultado da Análise dos Componentes Principais (PCA) das características anatômicas das folhas de $C$.xanthoarpa e correlação das características com os três eixos

\begin{tabular}{lccc}
\hline Eixo & Autovalores & \%Variância & $\begin{array}{c}\text { \%Variância } \\
\text { acumulada }\end{array}$ \\
\hline 1 & 3,62 & 48,03 & 48,03 \\
2 & 1,61 & 23,06 & 71,09 \\
3 & 1,32 & 18,83 & 89,92 \\
& & Autovetores & \\
Variável & $\mathbf{1 ~ E i x o}$ & $\mathbf{2 ~ E i x o ~}$ & $\mathbf{3 ~ E i x o}$ \\
\hline Esp. Total limbo & $\mathbf{- 0 , 5 2 8}$ & 0,030 & 0,061 \\
Esp. mesofilo & $\mathbf{- 0 , 5 4 2}$ & $-0,005$ & $-0,033$ \\
Par. paliçádico & $-0,422$ & 0,495 & $-0,007$ \\
Par. lacunoso & $-0,480$ & $-0,361$ & $-0,047$ \\
ep. abaxial & 0,109 & 0,030 & 0,685 \\
ep. adaxial & $-0,045$ & $-0,104$ & 0,704 \\
Rel. pal/lacun & 0,051 & $\mathbf{0 , 7 8 1}$ & 0,036 \\
\hline
\end{tabular}

\section{Conclusão}

Considerando que a guabiroba (Campomanesia xanthocarpa Berg.) é uma das principais espécies ocorrentes em formações vegetacionais da região centro-sul do estado do Paraná e em particular do município de Guarapuava e região, o conhecimento de características anatômicas, morfológicas e ecológicas desta espécie são bastante relevantes para futuros estudos e planos de manejo e/ou recuperação de áreas degradadas.

No presente estudo, foram obtidas algumas informações importantes sobre a estrutura desta espécie com relação a condição luminosa em que a mesma se encontra. Neste sentido, podemos caracterizar as plantas presentes em ambientes sombreados como tendo folhas maiores, com maior número de estômatos e uma lâmina foliar bem desenvolvida. Tais características estão basicamente relacionadas com um maior investimento na captura de energia luminosa para um processo fotossintético com taxas mais elevadas. As plantas que se desenvolvem a pleno sol não apresentam deficiência na disponibilidade de luz o que levou a desenvolverem características foliares estruturais (valores dos parâmetros morfológicos e anatômicos) intermediárias. Por fim, em ambiente de meia sombra as características estruturais encontradas, principalmente anatomicamente, estiveram mais próximas daquelas plantas desenvolvidas em ambiente aberto, devido provavelmente à contínua presença de luz promovida pelas aberturas artificiais das trilhas onde as plantas se encontravam, tendo apenas como barreira os ramos laterais de espécies de grande porte.

\section{Agradecimentos}

Os autores agradecem imensamente a Faculdade Guairacá por disponibilizar o espaço físico e equipamentos necessários ao desenvolvimento deste trabalho. 


\section{Referências}

ALVES DE BRITO, C. J. F.; ALQUINI, Y. A new method for staining botanical material ambedded in glycol - methacrylate (GMA). Arquivos de Biologia e Tecnologia, Curitiba, v.39, n.1, p.949-951, 1996.

BARDDAL, M. L.; RODERJAN, C. V.; GALVÃO, F.; CURCIO, G. R. Caracterização Florística e fitossociológica de um trecho sazonalmente inundável de Floresta Aluvial, em Araucária, PR. Ciência Florestal, Santa Maria, v.14, n.2, p.37-50, 2003.

BOEGER, M. R. T.; GLUZEZAK, R. M.; PIL, M. W.; GOLDENBERG, R.; MEDRI, M. Variabilidade morfológica foliar de Miconia sellowiana (DC.) Naudin (Melastomataceae) em diferentes fitofisionomias no Estado do Paraná. Revista Brasileira de Botânica, São Paulo, v.31, n.3, p.443-452, 2008.

BOEGER, M. R. T.; KAEHLER, M.; MELO JÚNIOR, J. C. F.; GOMES, M. Z.; OLIVEIRA, L. S.; CHAVES, C. R. M.; SCHOTTZ, E. S. Estrutura foliar de seis espécies do subosque de um remanescente de Floresta Ombrófila Mista. Hoehnea, São Paulo, v. 33, n. 4, p.521-531, 2006.

BOEGER, M. R. T.; WISNIEWSKI, C.; REISSMANN, C. B. Nutrientes foliares de espécies arbóreas de três estádios sucessionais de floresta ombrófila densa no sul do Brasil. Acta Botanica Brasilica, São Paulo, v.19, n.1, p.167-181, 2005.

CAMPOS, M.A.A.;UCHIDA, T. Influência do sombreamento no crescimento de mudas de três espécies amazônicas. Pesquisa Agropecuária Brasileira, Brasília, v.37, p.281-288, 2002.

CARDOSO-LEITE, E.; COVRE, T. B.; OMETTO, R. G.; CAVALCANTI, D. C.; PAGANI, M. I. Fitossociologia e caracterização sucessional de um fragmento de mata ciliar, em Rio Claro/SP, como subsidio à recuperação da área. Revista do Instituto Florestal, São Paulo, v. 16, n.1, p.31-41, 2004.

CASTRO, E. M.; PINTO, J. E. B. P.; ALVARENGA, A. A.; LIMA JÚNIOR, E. C.; BERTOLUCCI, S. K. V.; SILVA FILHO, J. L.; VIEIRA, C. V. Crescimento e anatomia foliar de plantas jovens de Mikania glomerata Sprengel (Guaco) submetidas a diferentes fotoperíodos. Ciência e Agrotecnologia, Lavras, v.6, p.1293-1300, 2003.

CASTRO-DIEZ, P.; PUYRAVAUD, J. P.; CORNELISSEN, J. H. C. Leaf structure and anatomy as related to leaf mass per area variation in seedlings of a wide range of woody plant species and types. Oecologia, v.124, n.4, p.476-486, 2000.

CORDEIRO,J.; RODRIGUES,W. A. Caracterização fitossociológica de um remanescente de Floresta Ombrófila Mista em Guarapuava,PR. RevistaÁrvore, Viçosa,v.31,n.3, p.545-554, 2007.

CORREA, M. P. Dicionário das plantas úteis do Brasil e das exóticas cultivadas. Rio de Janeiro: Imprensa Nacional, 1974. 512 p. (v.5). 
ESPÍNDOLA JÚNIOR,A.; BOEGER,M. R.T.; MACCARI JÚNIOR, A.; REISSMANN, C. B.; RICKLI, F. L. Variação na estrutura foliar de Mikania glomerata Spreng. (Asteraceae) sob diferentes condições de luminosidade. Revista Brasileira de Botânica, v.32, n.4,p.749-758, 2009.

FARIAS, J. A. C.; TEIXEIRA, I.F.; PES, L.S.; ALVAREZ FILHO, A. Estrutura fitossociológica de uma Floresta Estacional Decidual na região de Santa Maria, R.S. Ciência Florestal, Santa Maria, v.4, n.1, p. 109-128, 1994.

FRISCH, J.D.; FRISCH, C. D. Aves Brasileiras e Plantas que as Atraem. 3. ed. São Paulo: Dalgas Ecoltec-Ecologia Técnica Ltda., 2005. 480 p.

GUARAPUAVA-Prefeitura Municipal-Secretaria Municipal do Meio Ambiente.SEMAFLOR. Disponível em: <www.prefeituramunicipaldeguarapuava/>. Acesso em: 27 fev. 2010.

IVANAUSKAS, N. M.; RODRIGUES, R. R.; NAVE, A. G. Fitossociologia de um trecho de Floresta Estacional Semidecidual em Itatinga, São Paulo, Brasil. Scientia Forestalis, v.56, p.83-99, 1999.

JOHANSEN, D. A. Plant Microtechnique. New York: Mc Graw Hill Book, 1940.

KLEIN, R. M. Aspectos dinâmicos da vegetação do sul do Brasil. Selowia, n.36, p.5-54, 1984.

LIMA,A.R.; CAPOBIANCO,J.P.R.(Coords.).MataAtlântica: avanços legais e institucionais para sua conservação. Documentos do ISA n.004. Instituto Sócio Ambiental, Brasília. 1997.

MAACK, R.GeografiaFísicadoEstadodoParaná.2.ed. Rio de Janeiro: Nova Olympio,1981.450p.

MANTUANO, D. G.; BARROS, C. F.; SCARANO, F. R. Leaf anatomy variation within and between three "restinga" populations of Erythroxylum ovalifolium Peyr. (Erythroxylaceae) in southeast Brazil. Revista Brasileira de Botânica, v.29, n.2, p.209-215, 2006.

MATTOS, J. R. Myrtaceae do Rio Grande do Sul. Roessléria, v.6, n.6, p.3-394, 1984.

MILANEZE-GUTIERRE, M. A.; MELLO, J. C. P.; DELAPORTE, R. H. Efeito da intensidade luminosa sobre a morfo-anatomia foliar de Bouchea fluminensis (Vell.) Mold. (Verbenaceae) e sua importância no controle da qualidade da droga vegetal. Revista Brasileira de Farmacognosia, Maringá, v.13, n.1, p.23-33, 2003.

MONTANARI, R. M.; SOUSA, L. A.; LEITE, M. N.; COELHO, A. D. F.; VICCINI, L. F.; STEFANINI, M. B. Plasticidade fenotípica da morfologia externa de Lippia alba (Mill.) N.E. BR. ex Britt. \&Wilson (Verbenaceae) em resposta a níveis de luminosidade e adubação. Revista Brasileira de Plantas Medicinais, v.6, n.3, p.96-101, 2004.

MORAIS, H.; MEDRI, M. E.; MARUR, C. J.; CARAMORI, P. H.; RIBEIRO, A.M. A.; GOMES, J. C. Modifications on leaf anatomy of Coffea arabica caused by shade of Pigeonpea (Cajanus cajan). Brazilian Archives of Biology and Technology, v.47, n.6, p.863-871, 2004. 
REITZ, P. R. Mirtáceas. In: LEGRAND, C. D.; KLEIN, R. M. (Eds.). Flora Ilustrada Catarinense. Itajaí, Herbário Barbosa Rodrigues, 1977. [S.I.]

ROÇAS, G.; BARROS, C. F.; SCARANO, F. R. Leaf anatomy plasticity of Alchornea triplinervia (Euphorbiaceae) under distinct light regimes in a Brazilian montane Atlantic rain forest. Trees, v.11, n. 8, p.469-473, 1997.

SILVA, F. C.; MARCONI, L. P. Fitossociologia de uma Floresta com Araucária em Colombo-PR. Boletim de Pesquisa Florestal, Colombo, v.20, p.23-38, 1990.

SOUZA, V.C.; LORENZI, H. Botânica Sistemática. São Paulo: PLANTARUM,2005.640 p.

VOGELMANN, T. C.; NISHIO, J. N.; SMITH, W. K. Leaves and light capture: light propagation and gradients of carbon fi xation within leaves. Trends in Plant Science, v.1, n.2, p.65-70, 1996.

WILSON, P.J.; THOMPSON, K.; HODGSON, J. G. Specific leaf area and leaf dry matter content as alternative predictors of plant strategies. New Phytology, v.143,n.1, p.155-162, 1999. 